Relations industrielles

Industrial Relations

\title{
Les commissions d'industrie
}

Volume 1, numéro 2, octobre 1945

URI : https://id.erudit.org/iderudit/1023899ar

DOI : https://doi.org/10.7202/1023899ar

Aller au sommaire du numéro

Éditeur(s)

Département des relations industrielles de l’Université Laval

\section{ISSN}

0034-379X (imprimé)

1703-8138 (numérique)

Découvrir la revue

Citer cet article

(1945). Les commissions d'industrie. Relations industrielles / Industrial

Relations, 1(2), 3-3. https://doi.org/10.7202/1023899ar

Tous droits réservés (C Département des relations industrielles de l’Université Laval, 1945
Ce document est protégé par la loi sur le droit d'auteur. L’utilisation des services d'Érudit (y compris la reproduction) est assujettie à sa politique d'utilisation que vous pouvez consulter en ligne.

https://apropos.erudit.org/fr/usagers/politique-dutilisation/ 


\section{LES COMMISSIONS D'INDUSTRIE}

L'un des traits les plus caractéristiques de la vie industrielle moderne, consiste dans l'insuffisance marquée des institutions sociales et économiques en regard des progrès de la technique et de l'industrialisation. Celles qui s'avèrent incapables de s'ajuster et de se renouveler suivant les exigences du dynamisme de la vie périclitent sous le nombre des difficultés et des injustices qu'entraine souvent leur inertie. Ainsi, la guerre qui vient de finir, a créé un état de fait qui commande une adaptation générale et, dans bien des cas, des renouvellements de structure sans lesquels la vie même de maintes organisations se trouve en danger.

L'organisation internationale du Travail n'échappe pas à cette loi de la vie. Aussi procède-t-elle à un examen de sa structure en vue d'y apporter les perfectionnements qui lui permettront de résoudre efficacement les problèmes industriels modernes. Les commissions d'industrie en voie de formation sont un exemple du dynamisme de l'O.I.T. Par ces commissions d'industrie, elle va spécialiser davantage son activité. Comme par le passé, l'O.I.T. étudie les problèmes économiques et sociaux en vue de les résoudre par la fixation de bases internationales minima. Les commissions d'industrie sont un moyen de rendre l'action de l'O.I.T. plus directe et partant plus efficace.

Ces commissions d'industrie ont été formées par le Bureau international du Travail à la suite d'une décision du Conseil d'administration, mettant ainsi en pratique une recommandation de la Conférence de Philadelphie en 1944. Voici la liste des commissions d'industrie en voie d'organisation : $1^{\circ}$ bâtiment, travaux de génie civil et travaux publics ; $\mathscr{2}^{\circ}$ mines de charbon ; $\mathcal{S}^{\circ}$ transports internes ; $4^{\circ}$ production du fer et de l'acier ; $5^{\circ}$ industries métallurgiques $; 6^{\circ}$ production et raffinage du pétrole ; $7^{\circ}$ industrie textile. Ces commissions ont une représentation tripartite : les gouvernements, les travailleurs et les employeurs de ces diverses industries. Le Canada fera partie de chacune de ces commissions d'industrie.

Pourquoi, plus précisément, l'O.I.T. a-t-elle créé ces organismes de relations industrielles? Les commissions d'industrie ont été organisées parce qu'aucune procédure ne permettait de mobiliser toute la puissance du travail effectué par les ouvriers dans la même industrie ou le même métier. Les travailleurs appartenant au même métier ou à la même industrie ont en commun des besoins et des problèmes particuliers. Il en est de même des employeurs exploitant des industries similaires. Chaque commission établira elle-même son programme d'action pour l'avenir. Au début, le rôle de ces commissions consistera à provoquer des échanges de vues entre les gouvernements, les employeurs et les travailleurs des industries concernées. Ces échanges de vues seront le prélude de conventions internationales dont profiteront les employeurs et les travailleurs. Ce nouveau mécanisme de collaboration industrielle internationale veut être une contribution concrète à l'embauchage intégral, à l'amélioration des conditions de travail et au bien-être social des ouvriers.

\section{LA FÉDÉRATION NATIONALE DES TRAVAILLEURS DE LA PULPE ET DU PAPIER}

Le mois dernier, la Fédération nationale des travailleurs de la pulpe et du papier (affiliée à la C.T.C.C.) a tenu son congrès annuel à Kénogami. Après vingt-deux ans d'existence, la Fédération connaît maintenant des succès durables. Elle compte vingt-trois syndicats affiliés et elle est signataire de vingt-quatre conventions collectives de travail. Ses membres ont augmenté dans une proportion d'environ $20 \%$ au cours de l'année. Dans son rapport, le président, M. L.-P. Lessard,asoulignél'espritdecoopérationdelaplupartdesemployeursde cette industrie. Des efforts seront faits en vue de généraliser la coutume d'accorder deux semaines de vacances payées. Depuis 1942, la Fédération a obtenu pour ses travailleurs des augmentations de salaires d'environ un million et demi de dollars par année. Notons que la Fédération incite les travailleurs à faire leur part dans l'effort de réduction du côt de la production des entreprises, afin que l'industrie de la pulpe et du papier puisse conserver ses débouchés extérieurs et en acquérir de nouveaux.

\section{CONGRES OUVERTS !}

Il y a quelques mois, une importante association patronale prenait l'initiative d'inviter des chefs ouvriers à assister à l'une des séances de son congrès annuel. Récemment, deux associations ouvrières profitaient également de leurs congrès pour inviter quelques employeurs à suivre une partie de leurs délibérations. Nous croyons que ce geste devrait être imité par d'autres associations patronales et ouvrières. C'est là une façon de manifester la solidarité qui existe entre le Capital et le Travail à l'intérieur de chaque industrie. D'autre part, le Gouvernement déléguant toujours un représentant à ces divers congrès, toutes les parties intéressées ont alors l'occasion d'envisager en commun les problèmes qui relèvent de leur compétence. Ainsi, à l'esprit de classe succédera graduellement un esprit de collaboration et d'entente, et tout le monde en profitera. 